The University of San Francisco

USF Scholarship: a digital repository@ Gleeson Library |

Geschke Center

Sport Management

College of Arts and Sciences

2017

\title{
What Drives Endorsement Earnings for Superstar Athletes?
}

DANIEL RASCHER

RASCHER@USFCA.EDU

Terry Eddy

University of Arkansas, Fayetteville, tweddy@uark.edu

OSKR, LLC

Follow this and additional works at: http://repository.usfca.edu/sm

Part of the Sports Management Commons

\section{Recommended Citation}

RASCHER, DANIEL; Eddy, Terry; and OSKR, LLC, "What Drives Endorsement Earnings for Superstar Athletes?" (2017). Sport Management. 9.

http://repository.usfca.edu/sm/9

This Article is brought to you for free and open access by the College of Arts and Sciences at USF Scholarship: a digital repository @ Gleeson Library | Geschke Center. It has been accepted for inclusion in Sport Management by an authorized administrator of USF Scholarship: a digital repository @ Gleeson Library | Geschke Center. For more information, please contact repository@usfca.edu. 
What Drives Endorsement Earnings for Superstar Athletes?

\author{
Daniel A. Rascher (corresponding author) \\ University of San Francisco \\ Kalmanovitz Hall 241A \\ 2130 Fulton St., San Francisco, CA 94117 \\ 1-510-387-0644 \\ rascher@usfca.edu \\ Terry Eddy \\ University of Arkansas \\ College of Education and Health Professions \\ HPER 310B, 155 Stadium Drive \\ Fayetteville, Arkansas 72701 \\ Giseob Hyun \\ OSKR, LLC \\ 2200 Powell St., Suite 430 \\ Emeryville, CA 94608
}

For the Published Version of this Article, please visit:

Rascher, D., Eddy, T., \& Hyun, G. (2017). What Drives Endorsement Earnings for Superstar Athletes? Journal of Applied Sport Management, 9(2). 


\title{
What Drives Endorsement Earnings for Superstar Athletes?
}

\author{
Abstract \\ Athletes’ endorsement earnings receive significant attention in the trade/popular press, but the \\ academic literature on this issue is sparse. Thus, the purpose of the study was to examine factors \\ that drive variation in endorsement earnings. Resulting analyses indicated the Positive Q Score \\ measure (likability) was worth about $\$ 750,000$ - $\$ 1$ million for each unit of the scale, while the \\ Negative Q Score measure was statistically insignificant. One unit increases in Exposure and \\ Familiarity were worth roughly $\$ 600,000$ and $\$ 200,000$, respectively. These findings can be \\ used by athletes, agents, and sponsors to determine estimates, or fair-market value, for \\ endorsement deals.
}

Keywords - Endorsers, Q score, regression models, sport sponsorship, value

\section{Introduction}

The use of celebrities as endorsers continues to be a popular marketing strategy, as it is estimated that $15-25 \%$ of all advertisements in the United States feature celebrities (Ding, Molchanov, \& Stork, 2011; McGhee, 2012). As such, approximately \$1.6 billion is spent each year on athlete endorsements, with over $70 \%$ of that total going to only 100 athletes (Lawrence, 2013). Though research is somewhat mixed (Ding et al., 2011), it is generally accepted that endorsements, at worst, represent fair-value contracts (Fizel, McNeil, \& Smaby, 2008), and many times can have positive pay-offs in brand-level sales and significant increases in the firm's stock returns (Elberse \& Verleun, 2012). However, there is a dearth of research examining the value of an endorser independent of the brands for whom that individual is a spokesperson. As such, the purpose of this study was to investigate the drivers of superstar athletes’ annual endorsement earnings (e.g. exposure to the public, familiarity, likability). Understanding the 
market for hiring athletes as product endorsers is important for those in advertising, as well as for the athletes and their management teams.

Celebrity- and athlete-specific factors (including expertise, type of sport played, and demographic characteristics) have received some attention in past research on endorsements (Arai, Ko, \& Ross, 2014). In terms of expertise or on-field success, Elberse and Verleun (2012) found that endorsers that win multiple championships typically provide the best return to their brands, but even those that do not capture championships can create significant value if they are considered ‘top athletes'. This finding also follows some of the work using Ohanian’s (1991) model of source credibility, where expertise (on-field performance) is generally considered to be the most salient of the three categories of source credibility (Spry, Pappu, \& Cornwell, 2011). In some cases, athletes that possess significant athletic skill, but also pro-social behaviors and desirable personal trait characteristics, have been labelled 'hero' athletes (Stevens, Lathrop, \& Bradish, 2003). Hero athletes are generally very well-known and well-liked, and can generate tremendous endorsement power (Choi \& Rifon, 2012; Shuart, 2007). As such, many firms are willing to pay a premium for hero endorsers (Elberse \& Verleun, 2012).

One area that has received less attention is the impact associated with the sport an athlete plays. It has been suggested that the sport in which an athlete participates can have an effect on consumer evaluations of the endorsement (Martin, 1996), thereby affecting the value of endorsers from that sport. In more narrowly-focused studies involving between-sport differences, Sanchez and Sutton-Brady (2004) found that the image of the sport impacts endorsement fit and that there were differences between athletes participating in golf, soccer, and boxing. Additionally, Fizel et al. (2008) found that golf endorsements provided the only significant positive abnormal returns for the sponsoring company. 
In terms of demographic characteristics, gender and age have received the most attention in the literature. However, past findings are mixed - some studies have found male celebrities to be more effective endorsers (Boyd \& Shank, 2004), others have found females to be more effective (Charbonneau \& Garland, 2006), and yet others have found no differences on gender (Ding et al., 2011). Findings relative to age are also similarly mixed, as Ding et al. (2011) found a celebrity's age to not be a significant factor in a stock price event study, but Hsu and McDonald (2002) found younger endorsers to be more effective in a specific advertising campaign focused toward younger target markets.

\section{Method}

\section{Data Description}

The two main sources of data used in this study are the top fifty salaries and endorsements figures of U.S. professional athletes as reported in Sports Illustrated for 2004-2012 (SI 50), and the Q Scores of the athletes on the SI 50 compiled by The Q Score Company. There are 155 unique athletes within the 450 observations from the Sports Illustrated database, and details of the data collection methods can be found with the SI Top 50. Q Score variables come from annual surveys with respondents drawn from a nationally representative, balanced panel of 2,000 respondents (Marketing Evaluations, Inc., n.d.). Each athlete is rated as either "One of my Favorites”, "Very Good”, “Good”, “Fair”, “Poor”, or “Never Seen or Heard Before”. One hundred and thirteen (113) of the 450 observations did not have a Q Score for that year, reducing total observations to 337. Table 1 includes a summary of salaries and endorsement earnings.

$<<$ Insert Table 1 about here $>>$ 


\section{Variable Definitions}

Table 2 contains a summary of the dependent and independent variables for the 337 observations constituting the intersection of the SI 50 and the Q Scores. The dependent variable, Earnings, is simply each athlete's measure of endorsement earnings for a given year. The independent variables are defined as follows:

Salary - The individual athlete’s annual salary or earnings from their sport only.

Athletes - This is the number of athletes for a given "team" playing at any one time (e.g., 5 for basketball, 9 for baseball, 1 for tennis).

Total Games - The average annual number of contests played by the athlete. A boxer may be on television for 3 hours during a given year, while a tennis player may be on for 3 hours bi-weekly. Exposure - This is a separate measure of visibility created by dividing Total Games by Athletes. It is assumed that more games and fewer athletes in gameplay begets more camera coverage. Total Familiar - The Q Score Company's measure of the familiarity of the athlete. The average is about 64 , meaning that $64 \%$ of the people in the survey recognized the athlete. Positive Q Score - This is the number of respondents who answered "One of my Favorites" divided by Total Familiar. A positive impact on endorsement earnings is expected. Negative Q Score - This is the number of respondents who answered “Fair" or "Poor" divided by Total Familiar. It is expected that this will have a negative impact on endorsement earnings. Number of Years Professional - This is the tenure of the athlete (averages 9.8 years). It may account for an athlete's ability to build up a following over time or establish a personality. Sex - This is an indicator variable with female $=1$. Prior research has mixed findings on this so the a priori expectation is unknown.

Tennis, Baseball, Basketball, etc. - these are indicator variables denoting each sport. 
Year Indicator variables - These help control for time trends in the economy and endorsement market in particular. The Great Recession saw a downturn in the market with endorsements rising through 2008, dropping through 2010 (by 23\%,) and rising again through 2012.

$$
<<\text { Insert Table } 2 \text { about here }>>
$$

\section{Data Analysis}

The research design echoes the value proposition of individual athlete endorsers, framed by explanatory factors including expertise, likability, familiarity, exposure, and demographic characteristics. The model examines revealed endorsement value, given that the data is only for actual endorsements that the athletes have contracted, and not all products they could endorse.

The initial analysis relies on ordinary least squares regression (OLS) and uses all of the available independent variables. Regression analysis helps separate out the incremental impact of each explanatory factor on annual endorsement earnings. Given that some of the athletes appear in multiple years of the data, cross-sectional time series analyses were conducted. As is the case with many time series, most of the variation is between athletes and not within athletes over time (Greene, 2010). This is also true structurally, given that endorsement contracts are for multiple years with payments often being somewhat flat across years.

\section{Results}

The first model in Table 3 (Linear 1) uses fixed effects for each sport and does not include Athletes, Total Games, or Exposure. Eighty-six percent of the variation in endorsement earnings across the athletes is explained by this model. The key variables (Familiarity, Positive Q Score, and Negative Q Score) show that those athletes who are more familiar earn an additional $\sim$ 350,000 for each percentage point of increase in familiarity. Similarly, those with a positive Q Score earn over \$500,000, all else equal, for each one percent increase in being 
selected “One of my Favorites.” Interestingly, negative Q Scores did not have an impact on earnings. Linear 2 replaces the sport-specific indicators with structural characteristics of those sports: the number of athletes on the playing surface at a given time, the number of games/events during the season, and exposure (games divided by athletes). The exposure variable is highly significant, driving nearly $\$ 800,000$ in additional endorsement earnings for each point increase. Positive Q Score is also highly significant (\$900,000 increase for each additional point).

Linear 3 accounts for the significant correlation between Positive Q Score and Negative Q Score by using the difference between the two (Difference in Q Score equals Positive Q Score minus Negative Q Score). The correlation between the two variables can cause the coefficients on those variables to be misleading. Thus, creating this single variable removes any correlation (due to the existence of only one variable) and allows for a robustness check of the results. Estimating multiple models allows for a check on the robustness and stability of the results, and as shown, the effects of the key variables of interest are consistent across the models. Moreover, this new variable measures the gap between positive and negative responses about an athlete in the survey, allowing for a measure of relative likability to be tested. This new variable is highly statistically significant with a coefficient of about $\$ 500,000$. The impact of the exposure variable is similar to that in Linear 2.

On average, an athlete appears in the data 3.3 times or years (minimum of one, maximum of nine). As shown in RE GLS 1 (random effects), most of the variation is explained by differences between athletes, not within the same athletes over time. The exposure variable is similar with a coefficient of about $\$ 600,000$. Between 1 and Between 2 are between-group GLS analyses designed to control for Total Games and Athletes being correlated. However, the exposure variable is still worth around $\$ 500,000$ for each unit increase in exposure. 
Between 2 uses the Difference in Q Scores in place of Positive Q Score and Negative Q Score. The results are similar in that exposure and Difference in Q scores are associated with about $\$ 500,000$ increases for one point changes in each variable. It is important to note that Sex contains only four observations that are not zero (male): Michelle Wie, Venus Williams, and Serena Williams (twice). Essentially, it is almost an indicator variable for tennis, but removing it from the analyses does not change the impacts of the other variables (other than for Tennis).

\section{$<<$ Insert Table 3 about here $>>$}

\section{Discussion}

The purpose of this study was to investigate the impact of relevant predictors on superstar athletes' endorsement earnings. The model holds obvious practical implications, in that it could be used to determine a priori estimates (or future value) for endorsement deals, which could be beneficial for the companies that use athletes in advertising, as well as the athletes or sport agents who represent athletes’ marketing interests. An athlete’s relevant information can be inputted into the model, and the result can then be used to negotiate terms with interested brands. Of the variables in the model, Exposure, Positive Q Score (or Difference in Q Score), Familiarity, and sport played had significant effects on endorsement earnings. Specifically, if an athlete can improve their familiarity or likability by as little as 1 Q-score point, the model would suggest that they could see an aggregate increase of $\$ 750,000$ - \$1 million (or 1.5-2\%).

Additionally, the findings in this study illuminate which characteristics brands believe are important in an endorser, and provide insight into what the market is willing to pay for those characteristics. Therefore, advertisers could use the models to identify prospective endorsers that may be undervalued by the market, but still have the desired personality attributes for a particular campaign. For example, an NFL athlete that scores highly on likability and familiarity may 
come at a lower price than a similar scoring athlete from golf or tennis, but could still bring as much value to the advertising campaign.

Additionally, it seems reasonable to suggest that the likability and familiarity of an athlete to the public may be within some degree of control for advertisers. Is it possible that Michael Jordan's fame grew to stratospheric heights, in part, because of the power of Nike’s advertising campaigns and the Air Jordan brand, making him more familiar/likable to broader consumer segments? Would Peyton Manning score as highly on likability if not for his roles in humorous national campaigns that have become ingrained in popular culture? This proposition could be an important question for future research.

The increased goodness-of-fit when using the sport-specific variables shows that there are other factors that are not captured by exposure, number of athletes, or number of games/events per season (perhaps helmets covering the athletes' faces or the brutality of the sport, e.g., boxing and football). For example, the NFL receives arguably the most mainstream media coverage in the United States, yet NFL had a negative relationship with earnings. Future research should focus on gaining a better understanding of these between-sport differences.

Consistent with past research, athletes who played golf and tennis generally received higher endorsement earnings over the period in the study, but some of this positive relationship was driven by outliers (like Tiger Woods). It has been postulated that athletes in individual sports generate stronger sponsor impressions via television, and given that golf and tennis typically attract higher-income individuals, it is possible that companies are willing to pay more to endorse athletes in these two sports to gain access to these desirable target markets.

The models also highlight factors that are not predicting endorsement earnings among this sample of athletes. Although the number of years as a professional was the only direct 
measure of an athlete's quality (and was not statistically significant), the high explained variance suggested that athletic prowess is not playing a significant role in driving endorsement deals at the top levels of the market. Kobe Bryant could be an appropriate example here - he earns less endorsement money than his "peers”, despite being arguably the top player of his era, because his Q-scores are poor (likely stemming from his past legal issues). Thus, advertisers should be careful to not pay premiums for athletes solely because they demonstrate high levels of skill.

Additionally, the results of this study indicate that advertisers should consider long-term strategies that employ likable, up-and-coming athletes that have yet to attract national attention. These athletes will undoubtedly be cheaper than top stars, and their familiarity could be improved over time through their integration in a well-crafted advertising campaign. One recent campaign that may have exploited several of these possible inefficiencies was Verizon's ad series involving backup NFL quarterback Luke McCown. Exact figures were unavailable, but it seems likely that McCown was being paid significantly less than what a more well-known quarterback would demand. However, this clever campaign has received a significant amount of national attention, especially on social media (Wagner, 2015). Thus, this endorsement appears to have been effective in communicating a mundane product feature (backup cellular towers), and it seems reasonable to suggest that this campaign has also improved McCown’s familiarity.

It is important to note that there were no direct metrics included to measure fit between brand and athlete. Although the important fit-related concepts of expertise (Ohanian, 1991) and athletic hero status (Stevens et al., 2003) would have been partially caught by the salary, familiarity, and positive Q-score variables, these three factors are clearly not equivalent. Given the high goodness-of-fit in the models presented here, perhaps fit is less important to companies when determining endorsement earnings/value than we might believe. Additionally, while the 
familiarity and the likability of the athlete are captured in the data, respondents' attachment to the athlete is not captured. To the extent attachment matters, the statistical analysis is not predicting a major effect, perhaps because it is already being caught in the Q Score information.

Finally, although more extensive than some of the studies in the literature, the current sample was limited to the individuals on Sports Illustrated's Fortunate 50, which only includes 102 athletes during the sample period (resulting in 337 athlete-years). Additionally, the endorsement earnings data from SI are estimates, and the method by which SI collects these data (relying heavily on sports marketing executives and agents) could lead to some inaccuracies. However, it seems likely that any issues with the estimates (likely overestimation) would be consistent across the sample; thus, while some of the quantified findings could be somewhat inflated, the relationships between the variables should not differ. Future research should also expand outside of this list with a more global sample that also considers retired athletes.

\section{References}

Arai, A., Ko, Y. J., and Ross, S. (2014), “Branding athletes: Exploration and conceptualization of athlete brand image” Sport Management Review, Vol. 17 No. 2, pp. 97-106.

Boyd, T.C. and Shank, M. (2004), “Athletes as product endorsers: The effect of gender and product relatedness”, Sport Marketing Quarterly, Vol. 13 No. 2, pp. 82-93.

Charbonneau, J. and Garland, R. (2006), “The use of celebrity athletes as endorsers: Views of the New Zealand general public”, International Journal of Sports Marketing \& Sponsorship, Vol. 7 No. 4, pp. 326-333.

Choi, S.M. and Rifon, N.J. (2012), “It is a match: The impact of congruence between celebrity image and consumer ideal self on endorsement effectiveness”, Psychology and Marketing, Vol. 29 No. 9, pp. 639-650. 
Ding, H., Molchanov, A.E. and Stork, P.A. (2011), “The value of celebrity endorsements: A stock market perspective”, Marketing Letters, Vol. 22, pp. 147-163.

Elberse, A. and Verleun, J. (2012), “The economic value of celebrity endorsements.” Journal of Advertising Research, Vol. 52 No. 2, pp. 149-165.

Fizel, J., McNeil, C.R. and Smaby, T. (2008), “Athlete endorsement contracts: The impact of conventional stars”, International Advances in Economic Research, Vol. 14, pp. 247-256.

Greene, W. (2011), Econometric Analysis, $7^{\text {th }}$ edition, Prentice Hall, Upper Saddle River, NJ.

Hsu, C.K. and McDonald, D. (2002), “An examination on multiple celebrity endorsers in advertising”, Journal of Product \& Brand Management, Vol. 11 No. 1, pp. 19-29.

Lawrence, B. (2013), “Why big brands spend so much on athlete endorsements”, Opendorse, available at: http://opendorse.com/blog/why-big-brands-spend-so-much-on-athleteendorsements (accessed 2 November 2014).

Marketing Evaluations. (n.d.), “Methodology”, Marketing evaluations: The Q Scores Company, available at: http://www.qscores.com/web/default.aspx (accessed 10 October 2014).

Martin, J.H. (1996), “Is the athlete’s sport important when picking an athlete to endorse a nonsport product?”, Journal of Consumer Marketing, Vol. 13 No. 6, pp. 28-36.

McGhee, T. (2012), “The rise and rise of athlete brand endorsements”, Journal of Brand Strategy, Vol. 1 No. 1, pp. 79-84.

Ohanian, R. (1991), “The impact of celebrity spokesperson’s perceived image on consumers’ intention to purchase”, Journal of Advertising Research, Vol. 31 No. 1, pp. 46-52.

Sanchez, R. and Sutton-Brady, C. (2004), "Does sport matter? An analysis of the personality of sport”, Journal of Business \& Economics Research, Vol. 2 No. 11, 17-26. 
Shuart, J. (2007), “Heroes in sport: Assessing celebrity endorse, effectiveness”, International Journal of Sports Marketing \& Sponsorship, Vol. 8 No. 2, pp. 126-140.

Spry, A., Pappu, R. and Cornwell, T.B. (2011), “Celebrity endorsement, brand credibility and brand equity”, European Journal of Marketing, Vol. 45 No. 6, pp. 882-909.

Stevens, J.A., Lathrop, A.H. and Bradish, C.L. (2003), ““Who is your hero?” Implications for athlete endorsement strategies”, Sport Marketing Quarterly, Vol. 12 No. 2, pp. 103-110.

Wagner, L. (2015), “Career backup QB from Verizon commercial actually will play this weekend”, National Public Radio, available at: http://www.npr.org/sections/thetwoway/2015/09/25/443543283/career-backup-quarterback-from-verizon-commercialactually-gets-to-play-this-wee (accessed 24 October 2015).

\section{Table 1}

Endorsement Earnings by Sport

\begin{tabular}{|ccccc|}
\hline Sport & Count & $\begin{array}{c}\text { Average } \\
\text { Salary }\end{array}$ & $\begin{array}{c}\text { Average } \\
\text { Endorsement }\end{array}$ & $\begin{array}{c}\text { Ratio of } \\
\text { Endorsement to } \\
\text { Total Earnings }\end{array}$ \\
\hline Basketball & 140 & $\$ 16,198,507$ & $\$ 7,303,597$ & $31 \%$ \\
Baseball & 90 & $\$ 18,329,972$ & $\$ 2,786,389$ & $13 \%$ \\
Football & 45 & $\$ 16,677,110$ & $\$ 6,411,111$ & $28 \%$ \\
Auto Racing & 25 & $\$ 7,388,727$ & $\$ 15,406,946$ & $68 \%$ \\
Golf & 21 & $\$ 7,519,810$ & $\$ 50,314,286$ & $87 \%$ \\
Boxing & 8 & $\$ 40,125,000$ & $\$ 3,468,750$ & $8 \%$ \\
Tennis & 6 & $\$ 1,870,167$ & $\$ 23,500,000$ & $93 \%$ \\
Cycling & 2 & $\$ 478,750$ & $\$ 17,000,000$ & $97 \%$ \\
\hline \hline
\end{tabular}


Source: Sports Illustrated 
Table 2

Summary of Variables

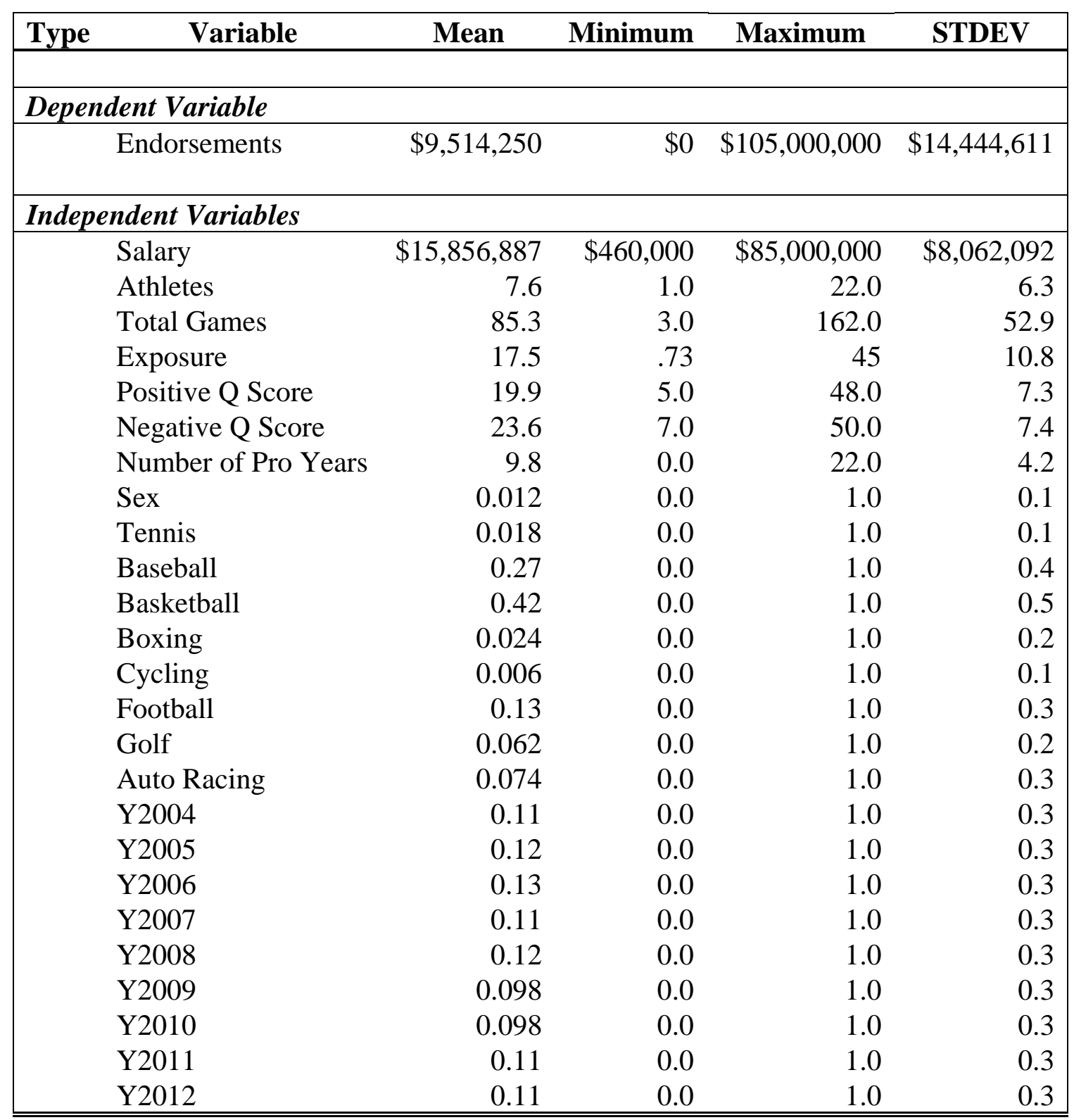

Notes:

$N=337$ 
Table 3

Endorsement Regression Models

\begin{tabular}{|c|c|c|c|c|c|c|c|c|c|c|c|c|}
\hline & Linear 1 & & Linear 2 & & Linear 3 & & RE GLS 1 & & Between 1 & & Between 2 & \\
\hline $\begin{array}{c}\text { Number of } \\
\text { Observations }\end{array}$ & 337 & & 337 & & 337 & & 337 & & 337 & & 337 & \\
\hline R squared & 0.8612 & & 0.6537 & & 0.4977 & & 0.6303 & & 0.5646 & & 0.4269 & \\
\hline Within & & & & & & & 0.1557 & & 0.0153 & & 0.0254 & \\
\hline Between & & & & & & & 0.6497 & & 0.6227 & & 0.4768 & \\
\hline F statistic & 44.16 & & 12.55 & & 8.4 & & & & 10.26 & & 6.17 & \\
\hline $\begin{array}{c}\text { Dependent } \\
\text { Variable }\end{array}$ & $\begin{array}{c}\text { Annual } \\
\text { Earnings }\end{array}$ & & $\begin{array}{c}\text { Annual } \\
\text { Earnings }\end{array}$ & & $\begin{array}{c}\text { Annual } \\
\text { Earnings }\end{array}$ & & $\begin{array}{c}\text { Annual } \\
\text { Earnings }\end{array}$ & & $\begin{array}{c}\text { Annual } \\
\text { Earnings }\end{array}$ & & $\begin{array}{c}\text { Annual } \\
\text { Earnings }\end{array}$ & \\
\hline Salary & -0.0727664 & & -0.0541583 & & -0.1211005 & & -0.0675839 & & -0.1889063 & & -0.229571 & \\
\hline 2004 & -9368490 & $* * *$ & -8747977 & $* * *$ & -1958029 & & -5642857 & $* * *$ & -7371611 & $*$ & 2708033 & \\
\hline 2005 & -5959112 & $* * *$ & -5608580 & $* *$ & 1238633 & & -2968983 & & -669589 & & 9916280 & $*$ \\
\hline 2006 & -5257905 & $* * *$ & -6378341 & $* * *$ & 18369.9 & & -2659475 & * & -3334994 & & 2564015 & \\
\hline 2007 & -5663746 & $* * *$ & -7936107 & $* * *$ & -1977704 & & -2811779 & $* *$ & -10000000 & $* *$ & -849457 & \\
\hline 2008 & -3000212 & $*$ & -4650809 & * & 2040224 & & 67331.83 & & -3182775 & & 6204738 & \\
\hline 2009 & -2309285 & * & -2771445 & & 3036275 & & 385675.4 & & -3361305 & & 3717298 & \\
\hline 2010 & -3315467 & $* * *$ & -5370624 & $* *$ & 2090115 & & -933503.8 & & -2134021 & & 10200000 & $*$ \\
\hline 2011 & -467791.3 & & -1371024 & & 4386305 & $*$ & 1637541 & & 281661.3 & & 8281081 & $*$ \\
\hline Sex & -27800000 & $* * *$ & -346587.4 & & 4611028 & & -595588.9 & & 630015.8 & & 2840957 & \\
\hline Tennis & 29900000 & $* * *$ & & & & & & & & & & \\
\hline Baseball & 1049584 & & & & & & & & & & & \\
\hline Basketball & 3567543 & & & & & & & & & & & \\
\hline Cycling & 2445154 & & & & & & & & & & & \\
\hline Football & -7560961 & $* * *$ & & & & & & & & & & \\
\hline Golf & 45200000 & $* * *$ & & & & & & & & & & \\
\hline Autoracing & 4008837 & & & & & & & & & & & \\
\hline Positive Q Score & 585705.1 & $* * *$ & 901565.4 & $* * *$ & & & 384826.4 & & 1192314 & $* * *$ & & \\
\hline $\begin{array}{c}\text { Negative Q Score } \\
\text { Difference in Q }\end{array}$ & 37536.91 & & 160549.9 & & & & -148599.7 & & 301113.3 & $* *$ & & \\
\hline Score & & & & & 488171.2 & $* * *$ & & & & & 448196.5 & $* * *$ \\
\hline $\begin{array}{c}\text { Familiar } \\
\text { Number of Pro. }\end{array}$ & 347044.6 & $* * *$ & 117197.7 & * & & & 219599.4 & $* * *$ & & & & \\
\hline Years & -880013.7 & $* * *$ & -475765.6 & $* *$ & -157367.1 & & -276479.2 & & -663930 & $* * *$ & -332836.6 & \\
\hline Athletes & & & 21584.19 & & & & -130270.6 & & & & & \\
\hline Total Games & & & -51377.01 & $* * *$ & & & -57451.32 & $* * *$ & & & & \\
\hline Exposure & & & 791535.3 & $* * *$ & 752972.9 & $* * *$ & 603595 & $* *$ & 549886.1 & $* * *$ & 539297.4 & $* * *$ \\
\hline Constant & -15700000 & $* * *$ & -19100000 & $* * *$ & 532545.4 & & -8491673 & & -18400000 & $* * *$ & 2263081 & \\
\hline
\end{tabular}

Significance: * 10\% level; ** 5\% level; *** 1\% level. 